\title{
Access to Medical and Mental Health Services Across the HIV Care Continuum Among Young Transgender Women: A Qualitative Study
}

\author{
Nadia Dowshen, ${ }^{1-3, *}$ Susan Lee, ${ }^{1,2}$ Joshua Franklin, ${ }^{3}$ Marné Castillo, ${ }^{1}$ and Frances Barg ${ }^{3}$
}

\begin{abstract}
Purpose: (1) To describe psychosocial, medical, and mental health outcomes of young transgender women (YTW) living with or at risk for HIV infection and (2) to explore barriers and facilitators to medical and mental health services across the HIV care continuum.

Methods: We conducted a cross-sectional observational study of YTW aged 16-24 years who were at risk for contracting or living with HIV. Participants were recruited from an adolescent HIV clinic and local communitybased organizations that serve YTW. The single study visit included: a computer-assisted self-interview of demographics, medical and mental health measures, a qualitative semi-structured interview, optional rapid HIV testing for HIV-negative/status-unknown participants, and a chart review to determine rates of antiretroviral therapy (ART) prescription and viral suppression among HIV+ participants. Descriptive statistics were used for quantitative data, and a modified-grounded theory approach was used for qualitative analysis.

Results: Participants $(n=25)$ had a mean age of 21.2 years; the majority were non-white $(76 \%)$, had less than a college education (76\%), were unemployed (52\%), and had an income $<\$ 12,000 /$ year (80\%). More than one-third were unstably housed (36\%) and uninsured (36\%), and $28 \%$ reported having transactional sex. A majority had taken gender-affirming hormones (72\%), but $17 \%$ obtained them from a source other than their doctor Among HIV+ participants $(n=8), 50 \%$ were prescribed ART and all four participants achieved viral suppression. Qualitative themes included lack of respect for or misunderstanding of gender identity, mismatch of mental health needs with available provider skills, challenges in finding HIV prevention services during adolescence or when transitioning to adult care, and importance of workforce diversity, including representation of transgender women in care teams.

Conclusion: This study identified significant unmet mental health needs and several barriers and facilitators to engaging in healthcare for YTW across the HIV care continuum. Our data suggest an urgent need for provider competency training in gender-affirming care and integration of appropriate mental health and genderaffirming treatment with HIV prevention and treatment services for this population.
\end{abstract}

Keywords: adolescence; HIV; mental health; qualitative methods; transgender

\section{Introduction}

Young transgender women (YTW), who are individuals assigned male sex at birth, but identify as female, face challenges to their physical and emotional wellbeing, including homelessness, joblessness, and victim- ization. ${ }^{1-9}$ These factors are believed to contribute to a high risk of HIV infection in this population, which is reported to be higher than $20 \%$ in multiple studies. ${ }^{1,10,11}$ In addition to threats to physical health such as HIV, transgender youth face significant mental

\footnotetext{
${ }^{1}$ Craig-Dalsimer Division of Adolescent Medicine, The Children's Hospital of Philadelphia, Philadelphia, Pennsylvania.

${ }^{2}$ PolicyLab, The Children's Hospital of Philadelphia, Philadelphia, Pennsylvania.

${ }^{3}$ Perelman School of Medicine, University of Pennsylvania, Philadelphia, Pennsylvania.
}

*Address correspondence to: Nadia Dowshen, MD, MSHP, Department of Pediatrics, The Children's Hospital of Philadelphia, 34th and Civic Center Boulevard, 11NW10, Adolescent Medicine, Philadelphia, PA 19104, E-mail: dowshenn@email.chop.edu

(C) Nadia Dowshen et al. 2017; Published by Mary Ann Liebert, Inc. This is an Open Access article distributed under the terms of the Creative Commons Attribution License, which permits unrestricted use, distribution, and reproduction in any medium, provided the original work is properly cited. 
health challenges. A recent multi-city study of 298 YTW at risk for HIV infection found that more than $40 \%$ had at least one mental health diagnosis. ${ }^{12}$ However, few data exist on the role of mental health co-morbidities and access to services across the HIV care continuum, including HIV testing and prevention, linkage and retention in care, and viral suppression, for YTW who are at a critical period of transition and identity development.

In addition, youth living with HIV infection (HIV+) have worse outcomes when compared with adults across the HIV continuum of care. Almost half are unaware of their diagnosis, and they are two to four times less likely to achieve viral suppression when compared with their adult counterparts. ${ }^{13,14}$ One recent study showed similar outcomes for HIV+ YTW who were linked to and engaged in care when compared with other behaviorally infected youth. ${ }^{15}$ However, although one qualitative study of HIV+ adult transgender women linked to care explored barriers and facilitators to engagement in care, little is known about the healthcare experiences of YTW across the HIV continuum of care. ${ }^{16}$

The objectives of this studies were: (1) to describe the psychosocial, medical, and mental health profiles of YTW living with or at risk for HIV infection and (2) to explore barriers and facilitators to medical and mental health services across the HIV care continuum.

\section{Materials and Methods}

Study subjects and recruitment

This qualitative study took place from February to December 2015 in Philadelphia, PA. Eligible subjects were: (1) transgender women (defined as those who were assigned male sex at birth with current female gender identity), (2) aged 16-24 years, and (3) with a HIV+ or HIV-negative (HIV-)/status-unknown YTW and who had unprotected anal intercourse in the past year. Participants were recruited consecutively from an adolescent HIV clinic and a clinic for transgender youth at a children's hospital, as well as through community-based organizations $(\mathrm{CBO})$ that provide services to youth living with or at risk for HIV or LGBT youth, and through social media. Initial contact was either (1) by phone, if a patient responded to a flyer posted at a CBO or electronically, or (2) in person in clinic. Informed consent was obtained, and all participants were provided with $\$ 25$ compensation on completion of the study visit for their time and effort. HIV-/status-unknown participants were provided with an additional $\$ 10$ if they also completed an optional rapid HIV test. The study was approved by the organization's Institutional Review Board.

\section{Data collection}

A single study visit consisted of a computer-assisted self-interview, ${ }^{17}$ a qualitative semi-structured interview, a medical chart review for HIV+ participants, and an optional OraQuick HIV-1/2 Rapid Test for HIV-/status-unknown participants.

One-on-one, open-ended, semi-structured interviews were conducted by four trained research assistants in private rooms in the Adolescent Clinic to elicit barriers and facilitators to services across the HIV care continuum. An interview guide, based on the Integrative Model of Behavioral Predication ${ }^{18,19}$ and the Social Ecologic Model, ${ }^{20}$ was developed (Appendix 1). Interviews were audio-recorded, transcribed, de-identified, and entered into NVivo (QSR International Pty Ltd. Version 10, 2012) for coding and analysis.

\section{Measures}

Participants completed questionnaires on demographic information, Behavior and Symptom Identification Scale (BASIS $\left.24^{\circledR}\right),{ }^{21}$ Quick Inventory of Depressive Symptomatology (QIDS-SR-16), ${ }^{22}$ Short Form Health Survey $\left(\mathrm{SF}-12^{\circledR}\right),{ }^{23}$ and AIDS Risk Behavior Assessment (ARBA). ${ }^{24}$

A chart review was completed for HIV+ participants to collect HIV-specific health outcomes (CD4 count, viral load) and information about antiretroviral therapy (ART) prescription.

\section{Quantitative analysis}

Analysis included standard descriptive statistics of demographics and psychological measures. Bivariate analyses were conducted by using chi-square test for categorical variables and $t$-test for a comparison of means.

\section{Qualitative analysis}

Key themes and patterns were identified by a team of coders by using a modified-grounded theory technique. ${ }^{25}$ The study team developed a codebook by reading each interview transcript, line by line, independently and identifying key ideas in the transcripts. We also included priori codes that were derived from the study question. Each key idea became a code with a definition, and decision rules were included in the codebook. A team of four coders double coded all transcripts. Using the inter-rater reliability function in NVivo, we checked agreement among coders and reviewed and revised any code that did not reach 95\% agreement among coders. The contents of each code were summarized and examined for patterns 
and themes. The quotations presented in this article have been edited by the author (N.D.) to protect the confidentiality of the study participants.

\section{Results}

\section{Demographics}

Participants $(n=25)$ had a mean age of 21.2 years (standard deviation 2.2, range 17-24); the majority were non-white, HIV-/status-unknown, publically insured or uninsured, unemployed, had less than a college education, and had an income less than $\$ 12,000$ / year (Table 1$)$. HIV+ subjects were more likely to identify as Black/African American $(p=0.002)$.

\section{Medical, psychosocial, and behavioral outcomes}

A high rate of gender-affirming hormone use (72\%) was found among YTW in this study, with $17 \%$ having obtained hormones from a source other than their medical provider (Table 2). Among HIV+ partici- pants, half were prescribed ART, which is similar to the proportion of all HIV+ youth in care nationally, ${ }^{14}$ and all subjects on ART had undetectable viral loads. Almost half of the participants had not used condoms at the time of their last sexual intercourse. High rates of depressive symptoms were found, with more than $60 \%$ of the sample meeting clinical criteria for moderate-to-severe depression. On the SF12 , participants overall were similar to the published general population norm ${ }^{23}$ for physical functioning, but below average for mental functioning. Also, HIV+ participants had lower (i.e., worse) physical composite scores $(p=0.045)$ but higher mental composite scores $(p=0.0006)$ when compared with HIV-/status-unknown participants.

\section{Qualitative results}

Several themes emerged regarding barriers to care in general healthcare, mental healthcare, and HIV prevention

\section{Table 1. Demographics by HIV Status}

\begin{tabular}{|c|c|c|c|c|}
\hline Demographics & Total cohort $(N=25)$ & HIV positive $(n=8)$ & HIV negative/unknown $(n=17)$ & $p$ \\
\hline Mean age at visit (SD, range) & $21.24(2.223,17-24)$ & $21.13(2.295,17-24)$ & $21.29(2.257,17-24)$ & 0.864 \\
\hline $\begin{array}{l}\text { Race } \\
\text { Multiracial, } n(\%) \\
\text { Black, } n(\%) \\
\text { White, } n(\%) \\
\text { Other, } n(\%)\end{array}$ & $\begin{array}{l}9(36) \\
7(28) \\
6(24) \\
3(12)\end{array}$ & $\begin{array}{c}1(12.5) \\
5(62.5) \\
0 \\
2(25)\end{array}$ & $\begin{array}{l}8(47.1) \\
2(11.8) \\
6(35.3) \\
1(5.9)\end{array}$ & 0.002 \\
\hline $\begin{array}{l}\text { Ethnicity, non-Hispanic } \\
\text { Sex at birth }\end{array}$ & $\begin{array}{c}20(80) \\
100 \% \text { Male }\end{array}$ & $7(87.5)$ & $13(76.5)$ & $>0.99$ \\
\hline $\begin{array}{l}\text { Gender (identify as) } \\
\text { Female, } n(\%) \\
\text { Transgender, } n(\%)\end{array}$ & $\begin{array}{r}7(28) \\
18(72)\end{array}$ & $\begin{array}{l}1(12.5) \\
7(87.5)\end{array}$ & $\begin{array}{r}6(35.3) \\
11(64.7)\end{array}$ & 0.313 \\
\hline $\begin{array}{l}\text { Highest level of education completed } \\
\text { High school graduate, } n(\%) \\
2 \text { Years of college/AA degree/technical } \\
\text { school training, } n(\%) \\
\text { College graduate or above, } n(\%)\end{array}$ & $\begin{array}{r}7(28) \\
12(48) \\
6(24)\end{array}$ & $\begin{array}{l}4(50) \\
2(25) \\
2(25)\end{array}$ & $\begin{array}{r}3(17.6) \\
10(58.8) \\
4(23.5)\end{array}$ & 0.294 \\
\hline $\begin{array}{l}\text { Estimated income } \\
\text { None or less than } \$ 600 / \text { year, } n(\%) \\
\$ 600-\$ 2999 / \text { year, } n(\%) \\
\$ 3000-\$ 5999 / \text { year, } n(\%) \\
\$ 6000-\$ 11,999 / \text { year, } n(\%) \\
\$ 12,000-\$ 35,999 / \text { year, } n(\%)\end{array}$ & $\begin{array}{l}7(28) \\
6(24) \\
4(16) \\
3(12) \\
1(4)\end{array}$ & $\begin{array}{c}3(37.5) \\
3(37.5) \\
0 \\
1(12.5) \\
0\end{array}$ & $\begin{array}{l}4(23.5) \\
3(17.6) \\
4(23.5) \\
2(11.8) \\
1(5.9)\end{array}$ & 0.676 \\
\hline Don't know, $n(\%)$ & $4(16)$ & $1(12.5)$ & $3(17.6)$ & \\
\hline $\begin{array}{l}\text { Employment status } \\
\text { Unemployed, } n(\%) \\
\text { Employed, } n(\%) \\
\text { Student, } n(\%)\end{array}$ & $\begin{aligned} 13 & (52) \\
5 & (20) \\
7 & (28)\end{aligned}$ & $\begin{array}{l}4(50) \\
1(12.5) \\
3(37.5)\end{array}$ & $\begin{array}{l}9(52.9) \\
4(23.5) \\
4(23.5)\end{array}$ & 0.736 \\
\hline $\begin{array}{l}\text { Current housing status } \\
\text { Stable, } n(\%) \\
\text { Unstable, } n(\%)\end{array}$ & $\begin{array}{r}16(64) \\
9(36)\end{array}$ & $\begin{array}{l}5(62.5) \\
3(37.5)\end{array}$ & $\begin{array}{r}11(64.7) \\
6(35.3)\end{array}$ & 0.763 \\
\hline $\begin{array}{l}\text { Insurance status } \\
\text { Insured, } n(\%) \\
\text { Uninsured, } n(\%)\end{array}$ & $\begin{array}{r}16(64) \\
9(36)\end{array}$ & $\begin{array}{l}2(25) \\
6(75)\end{array}$ & $\begin{array}{r}10(58.8) \\
7(41.2)\end{array}$ & 0.661 \\
\hline
\end{tabular}


Table 2. Behavioral and Health Outcomes of Young Transgender Women by HIV Status

\begin{tabular}{|c|c|c|c|c|}
\hline Health behavior and outcomes & Total cohort $(N=25)$ & HIV positive $(n=8)$ & HIV-negative/unknown ( $n=17$ ) & $p$ \\
\hline BASIS-24 score total, mean (SD, range $)^{a}$ & $1.54(0.83,0.14-3.17)$ & $1.41(1.04,0.14-3.17)$ & $1.60(0.73,0.36-2.61)$ & 0.705 \\
\hline Depression and functioning & $1.64(1.0,0-3.18)$ & $1.55(1.22,0-3.18)$ & $1.68(1.01,0.12-3.12)$ & 0.779 \\
\hline Emotional lability & $2.21(1.39,0-4.0)$ & $1.88(1.59,0-4.0)$ & $2.37(1.32,0.28-4.0)$ & 0.427 \\
\hline Relationships & $1.59(0.97,0-3.99)$ & $1.63(1.27,0.33-3.99)$ & $1.57(0.85,0-2.99)$ & 0.907 \\
\hline Psychosis & $1.17(1.21,0-4.0)$ & $1.09(1.29,0-4.0)$ & $1.2(1.21,0-3.86)$ & 0.843 \\
\hline Self-harm & $0.89(0.93,0-3.0)$ & $0.34(0.82,0-2.33)$ & $0.93(1.05,0-3.0)$ & 0.175 \\
\hline Substance abuse & $0.89(0.93,0-3.45)$ & $0.89(1.10,0-3.46)$ & $0.89(0.87,0-3.0)$ & 0.99 \\
\hline QIDS-SR-16 ${ }^{\mathrm{b}}$ & $11.4(5.89,0-27)$ & $8.63(5.6,0-16)$ & $12.71(5.7,4-27)$ & 0.108 \\
\hline SF-12: PCS (Physical Functioning) & $48.5(11.97,22.29-66.84)$ & $41.66(11.07,22.29-56.71)$ & $51.9(11.18,34.92-66.84)$ & 0.045 \\
\hline SF-12: MCS ${ }^{\mathrm{C}}$ (Mental Functioning) & $38.4(12.39,16.92-62.39)$ & $49.49(8.69,38.66-62.39)$ & $32.86(10.09,16.92-48.2)$ & 0.0006 \\
\hline Condom use at last sexual intercourse & & & & $>0.99$ \\
\hline Yes, $n(\%)$ & $14(56)$ & $5(62.5)$ & $9(52.9)$ & \\
\hline Ever given sex for money or drugs & & & & 0.639 \\
\hline Yes, $n(\%)$ & $7(28)$ & $3(37.5)$ & $4(23.5)$ & \\
\hline $\begin{array}{l}\text { Ever taken or currently taking medications } \\
\text { for gender transition }\end{array}$ & & & & 0.017 \\
\hline Yes, $n(\%)$ & $18(72)$ & $3(37.5)$ & $15(88.2)$ & \\
\hline $\begin{array}{l}\text { Gender transition medication } \\
\text { source (of } n=18 \text { ) }\end{array}$ & & & & 0.442 \\
\hline Provider only, $n(\%)$ & $15(83.3)$ & $2(13.3)$ & $13(86.7)$ & \\
\hline Ever from another source, $n(\%)$ & $3(16.7)$ & $1(33.3)$ & $2(66.7)$ & \\
\hline Currently on ART (of HIV,$+ n=8$ ), $n(\%)$ & & $4(50)$ & & \\
\hline \multicolumn{5}{|l|}{ Undetectable VL (of HIV+ on ART, $n=4$ ) } \\
\hline Undetectable, $n$ (\%) & & $4(100)$ & & \\
\hline \multicolumn{5}{|l|}{ HIV test (of HIV-/unknown, $n=17$ ) } \\
\hline Agreed to testing, $n(\%)$ & & & 14 (82.4) (All negative) & \\
\hline Refused, $n(\%)$ & & & $3(17.6)$ & \\
\hline
\end{tabular}

Bold indicates $p<0.05$.

${ }^{a}$ Higher score on BASIS-24 indicates greater severity.

${ }^{\mathrm{b}}$ Scoring for QIDS-16 is: 0-5, no depressive symptoms; 6-10, mild; 11-15, moderate; 16-20, severe; 21-27, very severe.

'SF-12 scale normalized at 50 with $\mathrm{SD}=10$.

and treatment. We discuss youth recommendations for improving care separately, including themes of specific provider characteristics, gender-affirming spaces, and integration of services as facilitators of engagement in care. In general, we did not find major differences in themes by HIV status, so results are reported in aggregate.

General healthcare. Previous negative experiences with providers, spaces, and systems. For many participants, previous negative experiences with healthcare providers, spaces, and administrative procedures became barriers to seeking healthcare. Several youth described particularly negative experiences in Emergency Department (ED) settings related to providers not respecting or understanding their gender identity, or paying undue attention to it even when it was not related to the presenting complaint.

I've had some doctors that I felt kind of treated me like a sideshow exhibit or something...I went into the hospital for suicidal ideation, and there was a doctor there that seemed very-I don't know how to put this-seemed very interested in me being a trans woman. He asked a lot of very invasive questions that had nothing to do with me-because I wasn't suicidal about my gender identity. I was suicidal for different reasons... and that's actually stopped me from seeking medical care for my depression and other things because I don't want to get sent back to a hospital where that's going to happen.

Registration processes and spaces such as waiting rooms were often felt to be unwelcoming and not appropriately designed for transgender individuals.

A lot of trans women feel that it's difficult to come into a space that's originally not for them, and that they feel like they have to come in with an extra barrier on, when they come into these places. Because they know that there's always going to be some...kind of silent prejudice. Because some health care professionals won't do it bold face in your face, they'll do it on a silent type of note. And like I guess, how we handle with health care, like with the forms. Forms are the first step, because once when you first walk in, you have to fill out a form. And the form can be very discouraging.

One youth describes how she was mistreated by other patients in addition to staff.

I just feel like I don't really want to go to the doctor because...they're gonna mistreat me. And other people, they sit next to me-they laugh and giggle and smile at my face and I'll be like, wow, that's really embarrassing. And it's very disappointing because I feel like they don't respect me.

Many participants describe feeling that providers invalidated their gender identity, specifically, by 
calling it a phase and glossing over it rather than offering support.

At that point I was identifying as gender queer.... And she goes, oh, it's just a phase. You'll grow out of it. And so I suppressed it for another six months. So, I think especially when it comes to emergency psychiatric care, there is a level of just lack of knowledge and unprofessionalism that accompanies gendered-variant people.

I think that my relationship with my doctors very early on set the tone for the rest of my life...know that even if a child is telling you things like-I'm a girl. I shouldn't have this kind of body. I think those are concerns you should take seriously. Even if it is just a phase or something like that, it's still useful to let a child know that no matter what they're going through...someone will support them and believe them.

In more extreme cases, youth were made to feel that their gender identity was wrong and something that needed to be corrected.

They made it seem like me being a woman of transgender experience is a problem and something that can be fixed. And it just made me extremely uncomfortable for me to hear from someone that's supposed to be helping me.

Practical socioeconomic concerns and fear of violence or legal consequences. Participants noted practical barriers that affect perceived or actual ability to obtain services such as insurance or cost of care.

I have a doctor's appointment tomorrow and the only reason that I'm going in to see my doctor tomorrow is so that I can sit down and talk with him about getting insurance...you need a job if you're going to be a trans woman, because at the end of the day, your hormones are very expensive.

Others reported concerns about physical safety when getting to appointments or facing legal consequences when being honest with doctors.

I know a lot of girls, especially who do sex work that are scared....You can't seek help from a police officer if you get robbed or anything. Because those experiences don't usually end up being positive. So sometimes you think that trying to get medical help...they just won't tell people the truth, because they're scared that they might get in trouble for it.

These concerns may be particularly relevant for YTW as opposed to other individuals at risk for HIV infection due to actual or perceived engagement in sex work that may lead to harassment, physical violence, and attention from law enforcement. ${ }^{26}$

Mental healthcare. Poor access to appropriate mental healthcare providers was cited as a major barrier to engaging in healthcare and achieving overall well-being. Several participants described not being able to find a mental health provider with expertise in genderaffirming care as well as more practical barriers such as cost or geographic proximity.
I was trying to get a therapist, and I was just having no luck with that....I had a very specific list of criteria...needs to be trans friendly, but doesn't need-not only a gender therapist.

Misunderstanding gender identity or inappropriate focus on it as the singular issue by mental health providers was a problem cited by several youth.

Me being trans is not why I can't get out of bed sometimes....And I once had a therapist where what I wanted to talk about was how I was having a lot of difficulty in school, how I couldn't concentrate, how I was feeling way too anxious all the time. But all she ever wanted to talk about was how I was trans, and she would be like, why do you want to become a girl? And I'm like, well, I mean, I'm a girl already. I got that settled....And I actually stopped seeing her because she was completely unhelpful.

Discrimination and harassment in emergency or inpatient psychiatric care, including staff actively participating in or condoning violent behavior toward transgender youth, was described.

I was homeless and suicidal. So, they put me [in a residential treatment facility]. I chose to go to that one because they told me I could be on the girls' floor.... When I get to this place, my mom signs me in. As soon as she leaves, they're like, all right. We're bringing you up to the guys' floor. There were no locks on the bathrooms. People walked in on me multiple times, which would be embarrassing enough....And because of that, they thought I was making them gay, got really angry at me and started beating me up. And no one used the right name. The staff made fun of me. It wasn't like it was just the kids. The staff-we had a community meeting....and they would openly ridicule me.

HIV prevention and treatment. Emotional and attitudinal barriers cited to HIV and sexually transmitted infection testing included nervousness, shame about previous behaviors, and fear of consequences of a positive result.

I had sex without a condom and it was sort of a, I-knew-better attitude that I had. And that delayed me getting tested for a while-fear. What would I do? What would happen if it came out positive? That's-I don't-it's like you try to be like, okay, if it turns out positive, nothing's gonna change, but we all know that that's a lie.

Several participants described typical factors such as substance abuse and depression as diminishing intention or decreasing priority to engage in HIV-related services.

When I was on drugs, I would kill myself. I didn't worry about getting tested. I didn't worry about who I was having sex with. I didn't worry about condoms...I was just doing what I had to do to get my next fix.

For HIV+ participants, many described being overwhelmed by multiple competing demands as a barrier to medication adherence. 
It's just because you have to-you have so much things that are-not that are more important, but that are, at least, in your face-more serious that you have to deal with and take care of that. So you lose sight of something as simple as taking a pill.

Challenges specific to the adolescent developmental context. Few participants noted being offered routine testing in primary care. One participant expressed concern about low testing rates in adolescents due to the lack of confidential sexual health discussion.

To not offer it. I'm just like, really? I understand it's important to talk about it, but as a physician it's also your responsibility to be like, hey, let's test you if you'd like to in the setting where your parents are in the waiting room, but they may not have to know, and that way you can get your results and feel safe.

Participants also cited practical barriers, including not knowing where to go to get tested and concerns about cost when transitioning to adult care.

Well, something that's been bugging me recently is I wanted to get a general panel of STD tests done, not just HIV, and when I was in college, that's easy to do. Because it was for free.... And that's easy. But I don't really know where to-I could probably figure it out, but I just haven't gotten around to it....So I haven't done that since I stopped being in school which was a year and a half ago.

Similar themes emerged with regard to pre-exposure prophylaxis (PrEP), taking a daily pill to prevent HIV infection, and these extensive and rich results are reported elsewhere. ${ }^{27}$

Recommendations for improving care. Increasing provider competency in gender-affirming care was the most common suggestion.

Treat us like women. Don't treat us like a freak of nature. Don't treat us like a different category. We're telling you we're women. Get on with it. Ask us about our names. What name do you want to be called? What do you want me to call this part of your body? How do you want me to talk about sex with you so that we can be up front and honest about making sure that you're having sex safely?

Provider relationship characteristics that facilitated maintaining one's health and adhering to healthcare were also described. Providers being open-minded and non-judgmental were among the most consistently mentioned positive attributes.

He just listened to what I had to say and then he would tell me his medical stuff and-I don't know-I didn't feel any different treatment because I was trans woman.

Participants also placed value not only on closeness and enduring relationships but also on having appropriate boundaries and being directive about what is needed to maintain health. These provider relationship characteristics were seen as motivation to adhere to medication among HIV+ participants.

I've had her for a couple years as my doctor, but she's like family to me-she's like that close with me, my doctor.

So like helping reminding me, like to make sure I'm taking medication, what I'm supposed to and things like that. I also like the relationship that we have.... It's like you know how some people just have doctors and it's just like oh, it's just their doctor.

Workforce diversity and representation of transgender women and positive experiences with LGBT-identified providers, "the doctor was actually trans himself", "he identified as queer...so he was very open minded," were seen as critical to engagement in care.

Probably the best possible thing that I can think of would be to have more of that treatment and testing run by trans women.

Integration of gender-affirming care with HIV services, at no or low cost, was viewed as critical to addressing multiple competing needs and facilitated engagement in care.

I'm pretty much-I just want to get as much service as I can. So I just take advantage of it, because it's not something that I have to pay for, thank goodness.... Because I've been transitioning.... So it's kind of like lumped it up together, because they do both of the stuff here.

Combination of practical strategies for access and promoting internal resilience. Online appointment access, more advertisements, financial incentives, and convenient location were suggested to improve access to HIV prevention services. Participants discussed social support from friends and pride in knowing one's status as motivators for getting HIV testing. Finally, internal attributes, including sense of personal responsibility, positive self-esteem, and future orientation, were viewed as facilitators to engagement in care.

I've been at every doctor's appointment. Nothing going to stop me from doing what I go to do because I'm trying to make a better situation for myself. I want to get somewhere in life. I'm not going to let HIV stop me from doing what I want to do or what I want to become.

\section{Discussion}

Several barriers and facilitators to medical and mental health services were identified across the HIV care continuum by YTW in this study. Participants described mostly negative and fragmented healthcare experiences across a variety of settings. In addition, our quantitative data indicate high levels of depressive symptoms and poor mental functioning on a quality-of-life measure. These findings were complemented by qualitative themes that emerged regarding difficulty in accessing 
appropriate mental health treatment. Further, despite significant risk, HIV testing and treatment was often not prioritized over other more basic needs and was associated with fear, shame, and stigma.

Barriers to optimal care were not only similar to those reported in other studies of transgender youth ${ }^{28,29}$ but also emphasized some unique issues and provided explanations that were specific to YTW both living with and at risk for HIV infection. For example, emergency departments were cited consistently as places where poor care was received due to the quality of interaction with providers, inflexible registration systems, and mismatch of patient need with the focus of care. This finding is not surprising given that a survey of more than 400 transgender people showed that $21 \%$ avoided seeking care in an ED because of fear of mistreatment, and $52 \%$ of individuals who sought care in an ED reported transgenderspecific negative experiences. ${ }^{30}$ This is a critical issue for YTW both living with and at risk for HIV infection since they are likely to seek care in the ED setting for multiple reasons, including their age, lack of access to other care, and high rates of suicide attempts. ${ }^{26,31}$

Our finding that more than half of the participants reported symptoms of moderate-to-severe depression is remarkable and consistent with findings from Reisner et al. ${ }^{12}$ However, our study adds important information about the mismatch between the unique mental health concerns of YTW and the failure of providers and systems to meet those needs. Participants in our study specifically described that few mental health providers were trained to address gender identity in the context of other mental health issues as well as not being able to afford or travel to appropriate providers when identified. They described their experiences of having their identities invalidated by providers as well as experiences of discrimination and humiliation, particularly in psychiatric emergency or inpatient mental health settings.

In contrast to the negative experiences of general and mental healthcare, more positive experiences were described in relation to HIV prevention and treatment, often when delivered by providers in LGBT-affirming spaces and where HIV care was integrated with gender transition care. These facilitators to HIV testing and treatment along with barriers reported by our participants related to stigma and competing needs were similar to those noted by Sevelius et al. in a sample of HIV+ adult transgender women. ${ }^{16}$ Our findings are also consistent with their combined theoretical model of Gender Affirmation and Health Care Empower- ment, which states that individuals are more likely to engage in HIV care when gender affirmation needs are met. ${ }^{32,33}$ Our study also adds the youth perspective that a healthcare workforce in which YTW see themselves reflected may lead to further empowerment and engagement in HIV prevention and treatment.

There are several limitations to this study. Because of the small sample size and qualitative methods, we cannot generalize the results to the larger population of YTW; rather, the results are hypothesis generating. We were also not able to stratify by various demographic factors because of the small sample, but we were able to reach a saturation of themes for the overall sample.

Despite these limitations, to our knowledge, this is one of the few qualitative studies to date of YTW both living with and at risk for HIV infection. Improved integration of mental health, primary care, and HIV services may help to address the myriad of barriers identified. In addition, similar to other studies of transgender youth, ${ }^{28}$ our data suggest an urgent need for development and implementation of genderaffirming competency training for all healthcare providers and that targeting emergency medicine and mental health providers may be especially critical. Finally, new primary and secondary HIV prevention interventions should be developed specifically for YTW, and they should possess the ability to be integrated with other services for these marginalized youth with competing needs.

\section{Acknowledgments}

The authors would like to thank the members of the study team for their efforts: Linda Hawkins, Breah Paciotti, Leeann Mao, Mark Meisarah, Derek Standlee, B. Matty Lehman, and Siobhan Gruschow. They are also grateful to Marilyn Schapira, David Rubin, and Robert Gross for their thoughtful feedback on this article. This research was supported by a grant from the Penn Mental Health AIDS Research Center (PMHARC), an NIH-funded program (P30 MH 097488) (PI: N.D.), and the National Institute of Mental Health (K23 MH 102128) (PI: N.D.).

\section{Author Disclosure Statement}

No competing financial interests exist.

\section{References}

1. Garofalo R, Deleon J, Osmer E, et al. Overlooked, misunderstood and atrisk: exploring the lives and HIV risk of ethnic minority male-to-female transgender youth. J Adolesc Health. 2006;38:230-236. 
2. Sanchez NF, Sanchez JP, Danoff A. Health care utilization, barriers to care, and hormone usage among male-to-female transgender persons in New York City. Am J Public Health. 2009;99:713-719.

3. Melendez RM, Exner TA, Ehrhardt AA, et al. Health and health care among male-to-female transgender persons who are HIV positive. Am J Public Health. 2006;96:1034-1037.

4. Nemoto T, Operario D, Keatley J, et al. HIV risk behaviors among male-tofemale transgender persons of color in San Francisco. Am J Public Health. 2004;94:1193-1199.

5. Sevelius JM, Reznick OG, Hart SL, Schwarcz S. Informing interventions: the importance of contextual factors in the prediction of sexual risk behaviors among transgender women. AIDS Educ Prev. 2009;21:113-127.

6. Wilson EC, Garofalo R, Harris RD, et al. Transgender female youth and sex work: HIV risk and a comparison of life factors related to engagement in sex work. AIDS Behav. 2009;13:902-913.

7. Operario D, Soma T, Underhill K. Sex work and HIV status among transgender women: systematic review and meta-analysis. J Acquir Immune Defic Syndr. 2008;48:97-103.

8. Grossman AH, D'Augelli AR. Transgender youth: invisible and vulnerable. J Homosex. 2006;51:111-128.

9. Mayer $\mathrm{KH}$, Bradford JB, Makadon $\mathrm{HJ}$, et al. Sexual and gender minority health: what we know and what needs to be done. Am J Public Health. 2008;98:989-995.

10. Herbst JH, Jacobs ED, Finlayson TJ, et al. Estimating HIV prevalence and risk behaviors of transgender persons in the United States: a systematic review. AIDS Behav. 2008;12:1-17.

11. Brennan J, Kuhns LM, Johnson AK, et al. Syndemic theory and HIV-related risk among young transgender women: the role of multiple, co-occurring health problems and social marginalization. Am J Public Health. 2012;102:1751-1757.

12. Reisner SL, Biello KB, White Hughto JM, et al. Psychiatric diagnoses and comorbidities in a diverse, multicity cohort of young transgender women: baseline findings from project lifeskills. JAMA Pediatr. 2016;170:481-486.

13. Gardner EM, McLees MP, Steiner JF, et al. The spectrum of engagement in HIV care and its relevance to test-and-treat strategies for prevention of HIV infection. Clin Infect Dis. 2011;52:793-800.

14. Zanoni BC, Mayer KH. The adolescent and young adult HIV cascade of care in the United States: exaggerated health disparities. AIDS Patient Care STDS. 2014;28:128-135.

15. Dowshen N, Matone M, Luan X, et al. Behavioral and health outcomes for HIV+ young transgender women (YTW) linked to and engaged in medical care. LGBT Health. 2016:3:162-167.

16. Sevelius JM, Patouhas E, Keatley JG, Johnson MO. Barriers and facilitators to engagement and retention in care among transgender women living with human immunodeficiency virus. Ann Behav Med. 2014;47:5-16.

17. Harris PA, Taylor R, Thielke R, et al. Research electronic data capture (REDCap) - a metadata-driven methodology and workflow process for providing translational research informatics support. J Biomed Inform. 2009;42:377-381.

18. Fishbein M, Guinan M. Behavioral science and public health: a necessary partnership for HIV prevention. Public Health Rep. 1996;111 Suppl 1:5-10.

19. Fishbein M. The role of theory in HIV prevention. AIDS Care. 2000;12:273278.

20. McLeroy KR, Bibeau D, Steckler A, Glanz K. An ecological perspective on health promotion programs. Health Educ Q. 1988;15:351-377.

21. Eisen SV, Normand SL, Belanger AJ, et al. The Revised Behavior and Symptom Identification Scale (BASIS-R): reliability and validity. Med Care. 2004;42:1230-1241.
22. Rush AJ, Trivedi $\mathrm{MH}$, Ibrahim HM, et al. The 16-Item Quick Inventory of Depressive Symptomatology (QIDS), clinician rating (QIDS-C), and selfreport (QIDS-SR): a psychometric evaluation in patients with chronic major depression. Biol Psychiatry. 2003;54:573-583.

23. Ware J, Jr, Kosinski M, Keller SD. A 12-Item Short-Form Health Survey: construction of scales and preliminary tests of reliability and validity. Med Care. 1996;34:220-233.

24. Donenberg GR, Emerson E, Bryant FB, et al. Understanding AIDS-risk behavior among adolescents in psychiatric care: links to psychopathology and peer relationships. J Am Acad Child Adolesc Psychiatry. 2001;40:642-653.

25. Charmaz K. Grounded theory: objectivist and constructivist methods. In: Handbook of Qualitative Research. (Denzin NK, Lincoln YS; eds.). Thousand Oaks: SAGE Publications, Inc., 2000.

26. James SE, Herman JL, Rankin S, et al. Executive Summary of the Report of the 2015 U.S. Transgender Survey. Washington, DC: National Center for Transgender Equality, 2016.

27. Wood SM, Lee S, Barg FK, et al. Young transgender women's attitudes toward HIV pre-exposure prophylaxis. J Adolesc Health. 2017 [Epub ahead of print]; DOI: 10.1016/j.jadohealth.2016.12.004

28. Gridley SJ, Crouch JM, Evans Y, et al. Youth and caregiver perspectives on barriers to gender-affirming health care for transgender youth. J Adolesc Health. 2016;59:254-261.

29. Corliss HL, Belzer M, Forbes C, Wilson EC. An evaluation of service utilization among male to female transgender youth: qualitative study of a clinic-based sample. J LGBT Health Res. 2007;3:49-61.

30. Bauer GR, Scheim Al, Deutsch MB, Massarella C. Reported emergency department avoidance, use, and experiences of transgender persons in Ontario, Canada: results from a respondent-driven sampling survey. Ann Emerg Med. 2014;63:713-720 e711.

31. Wilson KM, Klein JD. Adolescents who use the emergency department as their usual source of care. Arch Pediatr Adolesc Med. 2000;154:361-365.

32. Sevelius JM. Gender affirmation: A framework for conceptualizing risk behavior among transgender women of color. Sex Roles. 2013;68:675689.

33. Johnson MO. The shifting landscape of health care: toward a model of health care empowerment. Am J Public Health. 2011;101:265-270.

Cite this article as: Dowshen N, Lee S, Franklin J, Castillo M, Barg F (2017) Access to medical and mental health services across the HIV care continuum among young transgender women: a qualitative study, Transgender Health 2:1, 81-90, DOI: 10.1089/trgh.2016.0046.

$\begin{aligned} & \text { Abbreviations Used } \\ & \mathrm{ART}=\text { antiretroviral therapy } \\ & \mathrm{CBO}=\text { community-based organizations } \\ & \mathrm{ED}=\text { Emergency Department } \\ & \mathrm{PrEP}=\text { pre-exposure prophylaxis } \\ & \mathrm{YTW}=\text { young transgender women }\end{aligned}$




\section{Appendix 1. Semi-Structured Interview Script}

What are the perceptions of barriers and facilitators to engaging in HIV testing and treatment among young transgender women?

\section{Introduction}

1. The purpose of this interview is to help doctors and other healthcare providers understand how you experience medical care for HIV testing and/or treatment as a young trans ${ }^{\star}$ woman.

2. We believe that you're an expert, so we think that your opinion is really important to figure out what things might help make healthcare experiences for young trans ${ }^{*}$ women better.

3. Remember that you never have to answer any question if it makes you uncomfortable.

\section{Questions and Prompts}

1. Tell me about the last time you went to see a doctor. <wait for story >

$<$ If their relationship with the doctor is new, you can ask about their experiences with their previous doctor.> $<$ If they haven't been to the doctor in a while, you can ask what they did if they didn't feel well. $>$

\section{Prompts}

- How do you feel being a YTW affected the way you and your doctor interacted?

- What things did the medical provider do well? Not do well?

- What did they say about HIV testing? And how did that make you feel?

2. Tell me about the first time you got tested for HIV. <wait for story>

$<$ You can ask them to "walk me through your testing experience" $>$

\section{Prompts}

- How did you decide to get tested?

- What was it like for you?

- If you haven't been tested before, tell me about why you haven't gotten tested yet or why you decided not to. <If they've never been tested before, and their reason is "I just didn't," you can rephrase "What's the reason for that?" or "Why do you think that is?" >

3. (General testing questions)
[HIV+ only]

- What things have helped you or prevented you from

- Seeing the doctor once you found out you were positive?

- Taking your HIV medicines?

$<$ For HIV+ subjects, you can ask what they think current barriers are for trans ${ }^{*}$ girls getting tested.>

[HIV-/unknown only]

- If you were diagnosed with HIV, what things would help you or prevent you from

- Seeing the doctor once you found out you were positive?

- Taking your HIV medicines?

4. What do you think that most people believe about trans ${ }^{*}$ women and HIV?

Follow-up

- What do you think about that?

5. What kinds of things could make it easier or more comfortable for trans ${ }^{*}$ girls to get HIV testing and treatment?

Follow-up

Especially what kinds of things might help if they are sad or depressed?

$<$ If they don't bring up depression or feeling sad or down themselves, frame as "Up to now you haven't mentioned this, but we know from other research that many trans ${ }^{\star}$ girls have experienced anxiety or depression. Why do you think this is so? Do you think this affects how they experience medical care/testing?">

- What things have helped you or prevented you from getting tested?

$<$ You can break down a question if they respond with "I don't know," that is, talk about barriers to care, about what's a challenge with being YTW, what's a challenge to getting testing and treatment in general, and how to overcome those barriers and challenges they just talked about.>

6. What have you heard about PrEP or pre-exposure prophylaxis (i.e., taking a pill to prevent one from getting HIV)?

$<$ Be sure not to give medical advice when talking about PrEP. "Do you think I should go on it?" > 
Follow-up

- < If participant has heard of PrEP> Tell me about anything you have seen or heard or seen ads on social media, TV, or radio.

- How do you feel about PrEP for you and other trans ${ }^{\star}$ girls?

- < If the subject is HIV +> How do you feel about PrEP for a partner?

7. Many trans ${ }^{\star}$ girls have experienced depression or anxiety...

- Why do you think that is so?

- How has this been for you?

- What affects the way you feel?

- Did hormones or other treatments affect how you felt or how your friends who are trans ${ }^{\star}$ girls felt?
$<$ Use feelings of sadness as an opportunity to ask about depression and how it affects their experiences with medical care. For example, "You said that you felt sad about Tell me more about that. What other things affect how you feel? Do you think the way you feel makes it easier or harder to see the doctor or get tested? How have providers helped?">

$<$ If they give too general statements, ask "what kinds of situations," "tell me about the last time you were happy/sad," "what was it that made you felt happy recently? Tell me about that." >

8. What other thing do you feel healthcare providers need to know about being a trans ${ }^{\star}$ woman who may need care for HIV or other health issues?

9. Do I have your permission to call you about other studies in the future? 